\title{
Aldosterone synthase (CYP11B2) C-344T polymorphism affects the association of age-related changes of the serum C-reactive protein
}

\begin{abstract}
Kenji Oki ${ }^{1}$, Kiminori Yamane ${ }^{1}$, Kenichi Satoh ${ }^{2}$, Shuhei Nakanishi ${ }^{1}$, Hideya Yamamoto ${ }^{3}$ and Nobuoki Kohno ${ }^{1}$
Aldosterone participates in vascular and myocardial inflammation either directly or indirectly through blood pressure (BP). Aldosterone synthase (CYP11B2) C-344T polymorphism may influence the severity of systemic inflammation. A total of 398 Japanese Americans (152 men and 246 women, age 19-92 years) from the Hawaii-Los Angeles-Hiroshima study were enrolled. BP and serum levels of C-reactive protein (CRP) were measured, and the CYP11B2 C-344T polymorphism, rs 1799998, was determined. No influence of the polymorphism on baseline characteristics such as systolic, diastolic and mean BP, pulse pressure or serum CRP levels was observed. In all genotypes, systolic BP showed a significantly positive correlation with age (TT ( $n=178): r=0.283, P<0.001$; TC $(n=164): r=0.213, P=0.006$; and CC $(n=56): r=0.289, P=0.031)$. However, the regression coefficients of systolic BP with age were not different across genotypes. According to the results of univariate and multivariate analyses with adjustment for BP, the serum CRP level increased with age only in subjects with the CC genotype $(P=0.027$ and $P=0.004$, respectively), and elevation of serum CRP was mainly observed in the elderly population (aged $\geqslant 60$ years). Moreover, the regression coefficient of CRP levels with age was significantly steeper in subjects with the CC genotype than in those with the TC or TT genotype $(P=0.028)$. The CC genotype of the CYP11B2 C-344T polymorphism was associated with an age-dependent increase in the serum CRP level independent of BP, and may contribute to a cardiovascular phenotype by promoting vascular inflammation.
\end{abstract}

Hypertension Research (2010) 33, 326-330; doi:10.1038/hr.2009.233; published online 22 January 2010

Keywords: aldosterone; blood pressure; C-reactive protein; CYP11B2

\section{INTRODUCTION}

Aldosterone is well known to have an important role in the progression of cardiovascular diseases, such as hypertension and congestive heart failure. ${ }^{1,2}$ One of the polymorphisms of aldosterone synthase (CYP11B2), rs1799998, which is located $-344 \mathrm{bp}$ upstream and consistent with either Tor C, may influence the cardiovascular system through the effects of aldosterone, because the $\mathrm{C}$ allele binds to the steroidogenic factor-1 (SF-1) site five times stronger than does the T allele. $^{3}$

An overview of published studies suggests a higher frequency of hypertension or increase in blood pressure (BP) in subjects with the $\mathrm{T}$ allele or TT genotype as compared with that in subjects with the C allele or CC genotype, ${ }^{4-10}$ although several studies have reported the opposite association ${ }^{11,12}$ or the absence of any association. ${ }^{13-19}$ Thus, the associations remain controversial. Recently, two interesting studies have suggested a key indicator that may resolve the association. ${ }^{20,21}$ One is the observation of a significant increase in both systolic and diastolic BP with age in subjects with the T allele. ${ }^{20}$ The other is the observation, in the elderly population, of a significantly higher systolic BP in subjects with the TT genotype. ${ }^{21}$ These results suggest that the relationship between BP and the polymorphism may be affected by age.

Recent in vivo and in vitro studies have indicated that aldosterone not only mediates BP but also participates in vascular and myocardial inflammation through the activation of Src and generation of reactive oxygen species by NADPH oxidase, and is involved in the pathogenesis of atherosclerosis. ${ }^{22-24}$ Serum C-reactive protein (CRP) levels can reflect the severity of vascular or myocardial inflammation, ${ }^{25,26}$ and some clinical studies have shown that elevated serum CRP levels in healthy populations are predictive of vascular events, such as myocardial infarction and stroke. ${ }^{27,28}$ Although the association of aldosterone with inflammation has been established, there are no reports on the relationship between the CYP11B2 C-344T polymorphism and the serum levels of inflammatory markers such as CRP.

The aims of this study were to investigate (1) whether the polymorphism of CYP11B2 C-344T might be related to BP or

${ }^{1}$ Department of Molecular and Internal Medicine, Graduate School of Biomedical Sciences, Hiroshima University, Hiroshima, Japan; ${ }^{2}$ Department of Environmetrics and Biometrics, Research Institute for Radiation Biology and Medicine, Graduate School of Biomedical Sciences, Hiroshima University, Hiroshima, Japan and ${ }^{3}$ Department of Cardiovascular Medicine, Graduate School of Biomedical Sciences, Hiroshima University, Hiroshima, Japan

Correspondence: Dr K Yamane, Department of Molecular and Internal Medicine, Graduate School of Biomedical Sciences, Hiroshima University, 1-2-3 Kasumi, Minami-ku, Hiroshima-City, Hiroshima 734-8551, Japan.

E-mail: yamanek@hiroshima-u.ac.jp

Received 14 September 2009; revised 23 November 2009; accepted 13 December 2009; published online 22 January 2010 
serum CRP levels and (2) whether this polymorphism might bear an age-related interaction with BP and/or serum CRP levels in Japanese Americans.

It was reported that the subjects of this Japanese-American population-based study were at a higher risk of developing hypertension and atherosclerotic diseases than were Japanese subjects living in Japan, because of a westernized lifestyle. ${ }^{29}$ Therefore, we believed that this population might be the most appropriate to resolve the association of this polymorphism with the risk of development of hypertension and atherosclerotic diseases, because any genetic susceptibility to environmental factors would be more clearly expressed in this population as compared with that in Japanese subjects living in Japan.

\section{METHODS}

\section{Study population}

The study subjects were Japanese Americans enrolled in a medical survey conducted in 2004. The surveys have been described in detail elsewhere. ${ }^{29}$ Briefly, it is a long-term epidemiological study to detect the risk factors for hypertension, diabetes and atherosclerotic diseases in this population. The subjects were limited to those living in Los Angeles and genetically originating from the Japanese. To avoid the influence of diabetes mellitus and the use of antihypertensive drugs, subjects who were diabetic or receiving antihypertensive medications were excluded from the investigation. Finally, 152 men and 246 women, ranging in age from 19 to 92 years (mean age $=59.5$ years), were analyzed in this study. We confirmed, by medical history taking, that none of the subjects had any infectious symptoms, autoimmune diseases or other acute medical conditions. BP was measured using a mercury sphygmomanometer after the subjects had rested in the supine position for $5 \mathrm{~min}$. Pulse pressure and mean BP levels were calculated as systolic BP-diastolic BP and diastolic $\mathrm{BP}+1 / 3$ pulse pressure, respectively. Dyslipidemia was diagnosed as highdensity lipoprotein cholesterol $<40 \mathrm{mg}$ per $100 \mathrm{ml}$, total cholesterol $\geqslant 220 \mathrm{mg}$ per $100 \mathrm{ml}$, triglyceride $\geqslant 150 \mathrm{mg}$ per $100 \mathrm{ml}$ or in patients receiving antidyslipidemic treatment. Smoking status was assessed using standard interviewing procedures. Written informed consent was obtained from all subjects. This study was approved by the ethics committee of Hiroshima University and the Council of the Hiroshima Kenjin-Kai Association in Hawaii and Los Angeles.

\section{Sample collection}

After overnight fasting, venous blood samples were obtained in the morning. Blood samples were centrifuged, and the obtained serum was immediately frozen. Frozen samples were brought back to Japan and analyzed. Serum CRP was determined by an enzymatic method using a latex-enhanced immunonephelometric assay on a BNII analyzer (Dade Behring, Tokyo, Japan). ${ }^{30}$

\section{Genotyping}

Genomic DNA was extracted from peripheral leukocytes and stored at $-20^{\circ} \mathrm{C}$ until batch genotyping. Genotyping of the CYP11B2 C-344T polymorphism, rs1799998, was performed as described previously. ${ }^{17}$ It was amplified using EX Taq DNA polymerase (TaKaRa, Osaka, Japan) and the following primer set: forward primer 5'-CAT TTG TCA AAA CCC ACA GC-3' and reverse primer 5'-TCA CGT CAT GGG AGA ACT GG-3'. The PCR conditions were as follows: initial denaturation at $96^{\circ} \mathrm{C}$ for $5 \mathrm{~min}$, followed by 35 cycles at $96^{\circ} \mathrm{C}$ for $20 \mathrm{~s}$, annealing at $63^{\circ} \mathrm{C}$ for $30 \mathrm{~s}$, extension at $72{ }^{\circ} \mathrm{C}$ for $20 \mathrm{~s}$ and final extension at $72{ }^{\circ} \mathrm{C}$ for $5 \mathrm{~min}$. Digestion with the restriction enzyme Hae III resulted in bands of $234 \mathrm{bp}$ in the presence of the $\mathrm{C}$ allele and bands of $305 \mathrm{bp}$ in the presence of the $\mathrm{T}$ allele.

\section{Statistical analysis}

Quantitative data were expressed as means \pm s.d. During analysis, serum CRP levels were $\log$ transformed and expressed as medians (interquartile range), because they did not fit a normal distribution. We confirmed the normally distributed CRP levels after logarithmic transformation. Qualitative variables were expressed as percentages. Analyses were performed using SPSS for Windows (release 12.0; SPSS, Chicago, IL, USA). $P$-values $<0.05$ were considered to denote significance. Seven subjects with CRP levels $>10 \mathrm{mgl}^{-1}$ were excluded from the analyses, because values in this range indicate the possibility of acute inflammatory diseases. Allele and genotype frequencies were analyzed using the genecounting method, and the Hardy-Weinberg equilibrium, checked by the $\chi^{2}$-test, was considered to be maintained as described previously. ${ }^{13,17}$

First, statistical significance was determined by one-way ANOVA (analysis of variance) or by the $\chi^{2}$-test. In the case of statistically significant relations, the Bonferroni analysis was applied to assess the relationship between categories. Second, we performed Pearson's correlation analysis of age with systolic BP, diastolic BP, mean BP, pulse pressure and CRP in each genotype. Third, multiple regression analyses were conducted to investigate the associations between systolic BP, diastolic BP, mean BP and pulse pressure as dependent variables and age as an independent variable, after adjustments for sex, smoking status, body mass index and dyslipidemia in each genotype. Similarly, the association of serum CRP with age was determined by multiple regression analyses with adjustment for sex, smoking status, body mass index, dyslipidemia, fasting glucose and mean BP in each genotype. Fourth, we tested regression coefficients with age among the CYP11B2 genotypes by using a test of heterogeneity of slopes that represents a natural extension of the covariance analysis. For statistically significant associations, the Bonferroni analysis was applied to assess the relationships among categories. Finally, we investigated the curves relating age to serum CRP for each genotype $\left(y=a x^{2}+b x+c\right)$.

\section{RESULTS}

\section{Subject characteristics}

The clinical and biological characteristics of the subjects according to the three CYP11B2 genotypes are shown in Table 1. The genotype

Table 1 Clinical and biological characteristics of the study population

\begin{tabular}{|c|c|c|c|}
\hline & $T T(\mathrm{n}=178)$ & $T C(\mathrm{n}=164)$ & $C C(n=56)$ \\
\hline Sex (male/female) & $76 / 102$ & $58 / 106$ & $18 / 38$ \\
\hline Age (years) & $59.2 \pm 15.4$ & $59.2 \pm 12.8$ & $61.4 \pm 13.5$ \\
\hline $\mathrm{BMI}\left(\mathrm{kg} \mathrm{m}^{-2}\right)$ & $22.9 \pm 3.2$ & $23.9 \pm 3.5^{*}$ & $23.5 \pm 3.5$ \\
\hline Smoking (\%) & $71(39.9 \%)$ & $53(32.3 \%)$ & $16(28.6 \%)$ \\
\hline Systolic BP (mm Hg) & $131.2 \pm 17.4$ & $131.2 \pm 17.1$ & $130.4 \pm 14.2$ \\
\hline Diastolic BP (mm Hg) & $76.9 \pm 10.5$ & $76.9 \pm 10.9$ & $75.8 \pm 9.6$ \\
\hline Mean BP (mm Hg) & $95.0 \pm 11.8$ & $95.0 \pm 11.9$ & $94.0 \pm 9.1$ \\
\hline Pulse pressure (mm Hg) & $54.4 \pm 12.8$ & $54.3 \pm 12.6$ & $54.6 \pm 14.4$ \\
\hline Fasting glucose (mg per $100 \mathrm{ml}$ ) & $89.2 \pm 9.5$ & $89.2 \pm 10.2$ & $86.0 \pm 6.0$ \\
\hline Dyslipidemia (\%) & $115(64.6 \%)$ & $118(71.9 \%)$ & $43(76.8 \%)$ \\
\hline $\mathrm{CRP}\left(\mathrm{mg} \mathrm{I}^{-1}\right)$ & $0.64(0.30-1.37)$ & $0.67(0.36-1.35)$ & $0.69(0.33-2.11)$ \\
\hline
\end{tabular}

Abbreviations: ANOVA, analysis of variance; BMI, body mass index; BP, blood pressure; CRP, C-reactive protein. Continuous variables are expressed as means \pm s.d. or medians (interquartile range). Qualitative variables are expressed as percentages. Statistical significance was determined by one-way ANOVA

or $\chi^{2}$-test.
${ }^{*} P=0.028$ compared with TT. 
frequencies did not significantly deviate from the Hardy-Weinberg expectation. There were no significant differences in gender distribution, age, smoking status, systolic BP, diastolic BP, mean BP, pulse pressure, fasting glucose, prevalence of dyslipidemia or serum CRP levels among the genotypes. The body mass index of subjects with the TC genotype was significantly higher than that of those with the TT genotype $(P=0.028)$.

Relationships between BP and age in each genotype

The associations between BP and age were investigated by Pearson's correlation analysis for each genotype (Table 2). In all genotypes, systolic BP (TT: $r=0.283$ and $P<0.001$; TC: $r=0.213$ and $P=0.006$; and CC: $r=0.289$ and $P=0.031$ ) and pulse pressure (TT: $r=0.331$ and $P<0.001$; TC: $r=0.317$ and $P<0.001$; and CC: $r=0.481$ and $P<0.001)$ were significantly positively correlated with age, whereas a significant negative correlation between diastolic BP and age was found only in subjects with the CC genotype $(r=-0.293$ and $P=0.028)$ (Table 2$)$. Moreover, a significant positive correlation between mean BP and age was found only in subjects with the TT genotype $(r=0.179$ and $P=0.017$ ) (Table 2). The results of multiple regression analysis revealed that systolic BP was linked to age in subjects with the TT and TC genotypes (TT: $P=0.001$ and TC: $P=0.032$ ), and that pulse pressure was correlated with age in all genotypes (Table 3). Other correlations between BP and age were no longer significant after adjustments for the same variables (Table 3 ).

Interslope comparison of the age-BP relationship in each genotype Although systolic BP was correlated with age in subjects with the TT or TC genotype, the regression coefficients of systolic BP with age were not significantly different among genotypes (Table 3 ). The regression coefficients between diastolic BP and age tended to decrease from the

Table 2 Relationship of the clinical and biological characteristics with age in each genotype

\begin{tabular}{|c|c|c|c|c|c|c|}
\hline & \multicolumn{2}{|r|}{$T T$} & \multicolumn{2}{|c|}{$T C$} & \multicolumn{2}{|c|}{$C C$} \\
\hline & $r$ & P-value & $r$ & $\mathrm{P}$-value & $r$ & $\mathrm{P}$-value \\
\hline Systolic BP (mm Hg) & 0.283 & $<0.001$ & 0.213 & 0.006 & 0.289 & 0.031 \\
\hline Diastolic BP (mm Hg) & 0.066 & 0.384 & -0.033 & 0.678 & -0.293 & 0.028 \\
\hline Mean BP $(\mathrm{mm} \mathrm{Hg})$ & 0.179 & 0.017 & 0.082 & 0.300 & -0.057 & 0.678 \\
\hline Pulse pressure (mm Hg) & 0.331 & $<0.001$ & 0.317 & $<0.001$ & 0.481 & $<0.001$ \\
\hline $\mathrm{CRP}\left(\mathrm{mg} \mathrm{I}^{-1}\right)$ & 0.051 & 0.502 & 0.077 & 0.324 & 0.296 & 0.027 \\
\hline
\end{tabular}

Abbreviations: BP, blood pressure; CRP, C-reactive protein.

Values for CRP are converted to logarithms, because they did not fit a normal distribution. Results of Pearson's correlation analysis without any adjustment were indicated.
TT genotype to the CC genotype (Table 3). However, no significant difference in the regression coefficients of age and diastolic BP was observed among genotypes (Table 3 ). On the other hand, the regression coefficient of pulse pressure tended to be higher in subjects with the CC genotype than in those with the TC or TT genotype $(P=0.078)$ (Table 3).

Relationships between serum CRP and age in each genotype A significant positive relationship between serum CRP and age was observed in subjects with the CC genotype $(r=0.296$ and $P=0.027)$, but not in those with the TT or TC genotype (Table 2). The results of the multiple regression analysis revealed a correlation between serum CRP and age independent of the other variables only in subjects with the CC genotype $(P=0.004)$ (Table 3$)$. Furthermore, Figure 1 shows the curvilinear relationship between serum CRP and age in each genotype, and the differences were observed mainly in older subjects $(\geqslant 60$ years $)$.

Interslope comparison of the age-serum CRP relationship in each genotype

The correlation coefficient of serum CRP with age increased from the TT genotype to the CC genotype (Table 2); the correlation was

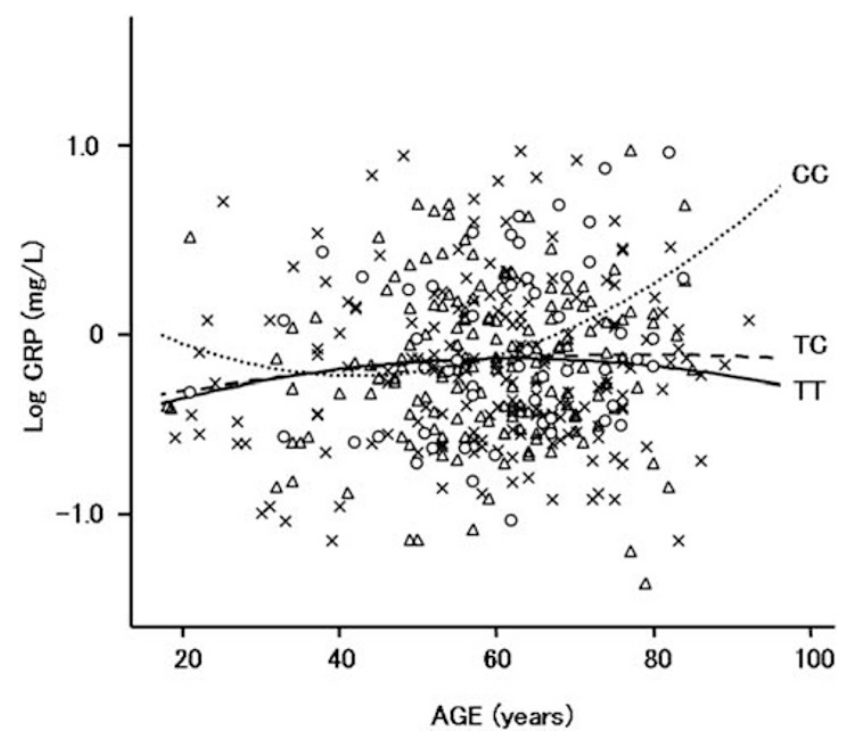

Figure 1 Association of the serum level of C-reactive protein (CRP) with age using a quadratic model for simple regression in subjects with the TT $(x)$, TC $(\Delta)$ and CC genotypes $(O)$. Log-transformed values of serum CRP were used for the analyses.

Table 3 Multiple regression analysis of regression coefficient with age among genotype and interslope comparison

\begin{tabular}{|c|c|c|c|c|c|c|c|}
\hline & \multicolumn{2}{|c|}{$T T$} & \multicolumn{2}{|c|}{$T C$} & \multicolumn{2}{|c|}{$C C$} & \multirow{2}{*}{$\begin{array}{c}\text { Interslope comparison } \\
\text { P-value }\end{array}$} \\
\hline & $\beta$ & $\mathrm{P}$-value & $\beta$ & P-value & $\beta$ & P-value & \\
\hline Systolic BP (mm Hg) & 0.256 & 0.001 & 0.218 & 0.032 & 0.288 & 0.074 & NS \\
\hline Diastolic BP (mm Hg) & 0.026 & 0.614 & -0.074 & 0.253 & -0.168 & 0.099 & NS \\
\hline Mean BP $(\mathrm{mm} \mathrm{Hg})$ & 0.102 & 0.064 & 0.024 & 0.735 & -0.016 & 0.884 & NS \\
\hline Pulse pressure $(\mathrm{mm} \mathrm{Hg})$ & 0.236 & $<0.001$ & 0.281 & $<0.001$ & 0.482 & $<0.001$ & NS \\
\hline $\mathrm{CRP}\left(\mathrm{mg} \mathrm{l}^{-1}\right)$ & 0.001 & 0.631 & 0.001 & 0.632 & 0.013 & 0.004 & 0.028 \\
\hline
\end{tabular}

Abbreviations: BMI, body mass index; BP, blood pressure; CRP, C-reactive protein; NS, not significant.

Multiple regression analyses were performed to investigate the associations of systolic BP, diastolic BP, mean BP and pulse pressure with age, after adjusting for sex, smoking, BMI, dyslipidemia and fasting glucose. The association of CRP with age was adjusted for sex, smoking, BMI, dyslipidemia, fasting glucose and mean BP. 
retained even after adjustment for the other variables (Table 3). After adjustments for the indicated variables, a significantly higher regression coefficient between age and serum CRP was found in subjects with the CC genotype compared with that in subjects with the TT or TC genotype $(P=0.028)$ (Table 3$)$.

\section{DISCUSSION}

We clarified that serum CRP level, a marker of systemic inflammation, increased with age only in the Japanese-American population with the CC genotype, but not in those with the TT or TC genotype. In contrast, the influence of age on BP did not differ significantly among genotypes. Thus, our study showed that elderly subjects with the CC genotype showed an elevation of serum CRP levels independent of BP.

Our results in which aldosterone synthase (CYP11B2) polymorphism directly influenced the serum level of the inflammation marker might be consistent with previous studies. Recent basic studies have reported that aldosterone promoted the inflammatory state through Src and p38 mitogen-activated protein kinases and NADPH oxidase activation in vascular smooth muscle cells. ${ }^{23,24}$ Furthermore, Suzuki et al. ${ }^{31}$ showed that although mineralocorticoid receptor blockade did not affect BP in male apolipoprotein E-deficient mice, it decreased the inflammatory response. Together with our study and those reports, the CYP11B2 C-344T polymorphism, as well as aldosterone itself, may possibly have direct effects on the systemic inflammatory state.

Both in vitro and in vivo studies have shown that aldosterone has an important pathophysiological role in atherosclerotic or cardiac diseases by promoting inflammatory changes. ${ }^{24}$ Progression of atherosclerosis leads to an increase in pulse pressure, thereby reducing the compliance of large blood vessels. ${ }^{32,33}$ As the regression coefficient of pulse pressure with age was approximately twofold higher in subjects with the CC genotype than in those with the TT or TC genotype in our study (Table 3 ), we considered that elderly subjects with the CC genotype tended to have high pulse pressure. In addition, two previous studies reported that the increase in PWV with increasing age independently of BP is most prominent in subjects with the CC genotype, ${ }^{34}$ and that the $\mathrm{CC}$ genotype might be an independent risk factor for the development of sodium-sensitive cardiac hypertrophy. ${ }^{17}$ Taken together, it is suggested that subjects with the CC genotype might have an amplification mechanism promoting the atherosclerotic process through inflammation, independently of BP.

We should consider the mechanism of the high risk for atherosclerosis in subjects with the CC genotype. It is reported that the polymorphism did not influence CYP11B2 expression through SF-1 regulation, although the $\mathrm{C}$ allele of CYP11B2 binds to SF-1, which suppresses CYP11B2 reporter activity, five times stronger than the T allele. ${ }^{3}$ On the other hand, there is positive association between left ventricular mass and sodium intake in subjects with the CC genotype. ${ }^{17}$ Accordingly, it is speculated that strong binding between the CYP11B2 promoter and SF-1 may inhibit prompt suppression of CYP11B2 by sodium loading in the CC genotype, resulting in an inappropriately higher level of aldosterone and sodium. It is reported that this population, as well as native Japanese, consumed a relatively high level of dietary salt, ${ }^{29,35}$ and thus high sodium intake might induce or exacerbate vascular inflammation through inappropriate suppression of aldosterone only in Japanese Americans with the CC genotype.

This study showed that BP did not differ among the genotypes. In keeping with the results of earlier studies, the associations of the CYP11B2 C-344T polymorphism with BP remain inconclusive. ${ }^{4-19}$ In addition, our results were not consistent with previous reports indicating that BP elevation was sensitive in elderly subjects with the
TT genotype. ${ }^{20,21}$ Furthermore, we suggested that the association of the CC genotype with CRP was consistent with previous reports describing the association of the genotype with cardiac structures and atherosclerosis as discussed above, ${ }^{17,34}$ whereas some apparent contradictory associations between the genotype and atherosclerosis, including cardiac structure and coronary artery diseases, have been shown in previous studies. ${ }^{36,37}$ As the associations of the genotype with BP and atherosclerosis are still uncertain, these differences could be explained in part by the allelic distribution or sodium intake related to ethnicity, elimination of subjects under antihypertensive drug treatment or insufficient sample size. Taken together, further clinical and basic investigations are required to clarify the relationship between the polymorphism and atherosclerosis.

Our study showed an age-dependent elevation of serum CRP independently of BP in subjects with the CC genotype as compared with those with the TT or TC genotype of the CYP11B2 C-344T polymorphism, and that this genotype may contribute to the cardiovascular phenotype by promoting vascular inflammation. Therefore, we suggest that it is important to consider the usefulness of aldosterone receptor blockade to avoid the development or progression of atherosclerotic diseases induced by aldosterone in subjects identified to have the CC genotype.

\section{CONFLICT OF INTEREST}

The authors declare no conflict of interest.

1 Matsumura K, Fujii K, Oniki H, Oka M, lida M. Role of aldosterone in left ventricular hypertrophy in hypertension. Am J Hypertens 2006; 19: 13-18.

2 Pitt B, Zannad F, Remme WJ, Cody R, Castaigne A, Perez A, Palensky J, Wittes J. The effect of spironolactone on morbidity and mortality in patients with severe heart failure. N Engl J Med 1999; 341: 709-717.

3 Bassett $\mathrm{MH}$, Zhang $\mathrm{Y}$, Clyne $\mathrm{C}$, White PC, Rainey WE. Differential regulation of aldosterone synthase and $11 \beta$-hydroxylase transcription by steroidogenic factor- 1 . $\mathrm{J}$ Mol Endocrinol 2002; 28: 125-135.

4 Fardella CE, Rodriguez H, Montero J, Zhang G, Vignolo P, Rojas A, Villarroel L, Miller WL. Genetic variation in P450c11AS in Chilean patients with low renin hypertension. J Clin Endocrinol Metab 1996; 81: 4347-4351.

5 Komiya I, Yamada T, Takara M, Asawa T, Shimabukuro M, Nishimori T, Takasu N. Lys(173)Arg and -344T/C variants of CYP11B2 in Japanese patients with low-renin hypertension. Hypertension 2000; 35: 699-703.

6 Brand E, Chatelain N, Mulatero P, Fery I, Curnow K, Jeunemaitre X, Corvol P, Pascoe L, Soubrier $F$. Structural analysis and evaluation of the aldosterone synthase gene in hypertension. Hypertension 1998; 32: 198-204.

7 Davies E, Holloway CD, Ingram MC, Inglis GC, Friel EC, Morrison C, Anderson NH, Fraser R, Connell JM. Aldosterone excretion rate and blood pressure in essential hypertension are related to polymorphic differences in the aldosterone synthase gene CYP11B2. Hypertension 1999; 33: 703-707.

8 Staessen JA, Wang JG, Brand E, Barlassina C, Birkenhager WH, Herrmann SM, Fagard R, Tizzoni L, Bianchi G. Effects of three candidate genes on prevalence and incidence of hypertension in a Caucasian population. J Hypertens 2001; 19: 1349-1358.

9 Barbato A, Russo P, Siani A, Folkerd EJ, Miller MA, Venezia A, Grimaldi C, Strazzullo P, Cappuccio FP. Aldosterone synthase gene (CYP11B2) C-344T polymorphism, plasma aldosterone, renin activity and blood pressure in a multi-ethnic population. $J$ Hypertens 2004; 22: 1895-1901.

10 Sookoian S, Gianotti TF, González CD, Pirola CJ. Association of the C-344T aldosterone synthase gene variant with essential hypertension: a meta-analysis. J Hypertens 2007; 25: $5-13$.

11 Tamaki S, Iwai N, Tsujita Y, Kinoshita M. Genetic polymorphism of CYP11B2 gene and hypertension in Japanese. Hypertension 1999; 33: 266-270.

12 Hautanena A, Lankinen L, Kupari M, Janne OA, Adlercreutz H, Nikkila H, White PC. Associations between aldosterone synthase gene polymorphism and the adrenocortical function in males. J Intern Med 1998; 244: 11-18.

13 Kato N, Sugiyama T, Morita H, Kurihara H, Furukawa T, Isshiki T, Sato T, Yamori Y, Yazaki Y. Comprehensive analysis of the renin-angiotensin gene polymorphisms with relation to hypertension in the Japanese. J Hypertens 2000; 18: 1025-1032.

14 Tsujita Y, Iwai N, Katsuya T, Higaki J, Ogihara T, Tamaki S, Kinoshita M, Mannami T, Ogata J, Baba S. Lack of association between genetic polymorphism of CYP11B2 and hypertension in Japanese: the Suita Study. Hypertens Res 2001; 24: 105-109.

15 Zhu H, Sagnella GA, Dong Y, Miller MA, Onipinla A, Markandu ND, MacGregor GA Contrasting associations between aldosterone synthase gene polymorphisms and essential hypertension in blacks and in whites. J Hypertens 2003; 21: 87-95. 
16 Schunkert H, Hengstenberg C, Holmer SR, Broeckel U, Luchner A, Muscholl MW, Kürzinger S, Döring A, Hense HW, Riegger GA. Lack of association between a polymorphism of the aldosterone synthase gene and left ventricular structure. Circulation 1999; 99: 2255-2260.

17 Isaji M, Mune T, Takada N, Yamamoto Y, Suwa T, Morita H, Takeda J, White PC. Correlation between left ventricular mass and urinary sodium excretion in specific genotypes of CYP11B2. J Hypertens 2005; 23: 1149-1157.

18 Casiglia E, Tikhonoff V, Schiavon L, Guglielmi F, Pagnin E, Bascelli A, Basso G, Mazza A, Martini B, Bolzon M, Guidotti F, Caffi S, Rizzato E, Pessina AC. Skin-fold thickness and blood pressure across C-344T polymorphism of CYP11B2 gene. J Hypertens 2007; 25: 1828-1833.

19 Yamagishi K, Tanigawa T, Cui R, Tabata M, Ikeda A, Yao M, Shimamoto T, Iso H. Aldosterone synthase gene T-344C polymorphism, sodium and blood pressure in a freeliving population: a community-based study. Hypertens Res 2007; 30: 497-502.

20 Russo P, Siani A, Venezia A, lacone R, Russo O, Barba G, D’Elia L, Cappuccio FP, Strazzullo P. Interaction between the C(-344)T polymorphism of CYP11B2 and age in the regulation of blood pressure and plasma aldosterone levels: cross-sectional and longitudinal findings of the Olivetti Prospective Heart Study. J Hypertens 2002; 20: 1785-1792.

21 Casiglia E, Tikhonoff V, Mazza A, Rynkiewicz A, Limon J, Caffi S, Guglielmi F, Martini B, Basso G, Winnicki M, Pessina AC, Somers VK. C-344T polymorphism of the aldosterone synthase gene and blood pressure in the elderly: a population-based study. $J$ Hypertens 2005; 23: 1991-1996.

22 Kotlyar E, Vita JA, Winter MR, Awtry EH, Siwik DA, Keaney Jr JF, Sawyer DB, Cupples LA, Colucci WS, Sam F. The relationship between aldosterone, oxidative stress, and inflammation in chronic, stable human heart failure. J Card Fail 2006; 12: 122-127.

23 Callera GE, Touyz RM, Tostes RC, Yogi A, He Y, Malkinson S, Schiffrin EL. Aldosterone activates vascular p38MAP kinase and NADPH oxidase via c-Src. Hypertension 2005; 45: 773-779.

24 Pitt B, Remme W, Zannad F, Neaton J, Martinez F, Roniker B, Bittman R, Hurley S, Kleiman J, Gatlin M. Eplerenone, a selective aldosterone blocker, in patients with left ventricular dysfunction after myocardial infarction. N Eng/ J Med 2003; 348: 1309-1321.

25 Torzewski M, Rist C, Mortensen RF, Zwaka TP, Bienek M, Waltenberger J, Koenig W, Schmitz G, Hombach V, Torzewski J. C-reactive protein in the arterial intima: role of $\mathrm{C}$-reactive protein receptor-dependent monocyte recruitment in atherogenesis. Arterioscler Thromb Vasc Biol 2000; 20: 2094-2099.
26 Pasceri V, Willerson JT, Yeh ET. Direct proinflammatory effect of C-reactive protein on human endothelial cells. Circulation 2000; 102: 2165-2168.

27 Blake GJ, Rifai N, Buring JE, Ridker PM. Blood pressure, C-reactive protein, and risk of future cardiovascular events. Circulation 2003; 108: 2993-2999.

28 Albert MA, Glynn RJ, Ridker PM. Plasma concentration of C-reactive protein and the calculated Framingham Coronary Heart Disease Risk Score. Circulation 2003; 108 : 161-165.

29 Yoneda M, Yamane K, Jitsuiki K, Nakanishi S, Kamei N, Watanabe H, Kohno N. Prevalence of metabolic syndrome compared between native Japanese and JapaneseAmericans. Diabetes Res Clin Pract 2008; 79: 518-522.

30 Rifai N, Tracy RP, Ridker PM. Clinical efficacy of an automated high-sensitivity C-reactive protein assay. Clin Chem 1999; 45: 2136-2141.

31 Suzuki J, Iwai M, Mogi M, Oshita A, Yoshii T, Higaki J, Horiuchi M. Eplerenone with valsartan effectively reduces atherosclerotic lesion by attenuation of oxidative stress and inflammation. Arterioscler Thromb Vasc Biol 2006; 26: 917-921.

32 Ryan SM, Waack BJ, Weno BL, Heistad DD. Increases in pulse pressure impair acetylcholine-induced vascular relaxation. Am J Physiol 1995; 268: H359-H363.

33 Shimoda T, Ishihata A, Aita T, Kaga M, Ito T, Ohwada K, Tomoike H, Katano Y. Progression of severe atherosclerosis and increased arterial pulse pressure in the newly developed heritable mixed hyperlipidaemic rabbits. Clin Exp Pharmacol Physiol 2006; 33: 221-226.

34 Safar ME, Cattan V, Lacolley P, Nzietchueng R, Labat C, Lajemi M, de Luca N, Bénétos A. Aldosterone synthase gene polymorphism, stroke volume and age-related changes in aortic pulse wave velocity in subjects with hypertension. J Hypertens 2005; 23: 1159-1166.

35 Stamler J, Elliott P, Kesteloot H, Nichols R, Claeys G, Dyer AR, Stamler R. Inverse relation of dietary protein markers with blood pressure. Findings for 10,020 men and women in the INTERSALT Study. INTERSALT Cooperative Research Group. International study of SALT and blood pressure. Circulation 1996; 94: 1629-1634.

36 Schunkert H, Hengstenberg C, Holmer SR, Broeckel U, Luchner A, Muscholl MW, Kürzinger S, Döring A, Hense HW, Riegger GA. Lack of association between a polymorphism of the aldosterone synthase gene and left ventricular structure. Circulation 1999; 99: 2255-2260.

37 Patel S, Steeds R, Channer K, Samani NJ. Analysis of promoter region polymorphism in the aldosterone synthase gene (CYP11B2) as a risk factor for myocardial infarction. Am J Hypertens 2000; 13: 134-139. 